\title{
MAGISTERBIBLIOTHEKEN AN DER PRAGER UNIVERSITÄT IM SPÄTMITTELALTER UND IN DER FRÜHEN NEUZEIT (KNAPPE SKIZZE)
}

\author{
IVAN HLAVÁČEK
}

\section{THE LIBRARIES OF THE MASTERS OF THE UNIVERSITY OF PRAGUE IN THE LATE MIDDLE AGES AND EARLY MODERN PERIOD}

The author of the paper attempts to capture the evolution of the libraries of individual university masters at the single-faculty post-Hussite university until its takeover by the Jesuit Academy at the beginning of the Thirty Years' War. He asserts that these libraries were frequently extensive in their scope and diversity of content; however, the material, to a large degree anonymous, is so fragmentary, and so little analytical work has yet been carried out to fully penetrate it, that a definitive conclusion cannot be drawn.

Keywords: University of Prague - libraries of university masters - end of the Middle Ages - early modern period - manuscripts - incunables

DOI: $10.14712 / 23365730.2020 .23$

Ohne Bücher und ohne Bibliotheken kein Studium, ja keine höhere Kultur überhaupt. Ich werde mich um eine Skizze des bescheidenen „Segments der Segmente“ dieser uferlosen Problematik bemühen, was jedoch zugleich bedeutet, dass es sich eher um eine Vogelschau handeln wird, ja muss. Man kämpft dabei mit immensem Quellenmangel, der aber spezifische Züge hat. Das bedeutet freilich nicht, dass für diese Zeit und Problematik wenig Material existierte, sondern dass damalige (reichhaltige) Unterlagen zum guten Teil eigentlich seit langem zu den Deperdita im breitesten Sinne des Wortes gehören. ${ }^{1}$ Darüber hinaus muss man stets im Auge behalten, dass die Verluste recht unregelmäßig verteilt sind, so dass manchmal eben die Schlüsselquellen fehlen und umgekehrt die am Rande des Hauptstroms stehenden den Blick in diesem Sinne einseitig machen und deshalb das Gesamtbild verdunkeln können. Und schließlich: während das Archivmaterial im Allgemeinen (das freilich für die uns interessierende Zeit und Problematik ebenfalls große Lücken aufweist) relativ große stabilitatem loci aufweist, ist das bei den (literarischen) Büchern in historischer Perspektive

1 Die optimistischen Schätzungen sprechen von maximal $7 \%$ erhaltener Handschriften, die pessimistischeren, d. h. realistischeren, sogar von kaum um die $3 \%$ (s. Franz LaCKNER, Katalog der Streubestände in Wien und Niederösterreich, Wien 2000, S. 7; nach Uwe NedDERMEYER, Schätzungen über das späte Mittelalter, in: Ders., Von der Handschrift zum gedruckten Buch, I, Wiesbaden 1998, S.72ff., vgl. jedoch die Rezension von Martina Hartmann - Arno Mentzel-Reuters, Deutsches Archiv 57, 2001, S. 712f.). Die konkreten Magister, die unten erwähnt werden, sind - soweit bekannt - biographisch in einem von Martin Holý und Mlada Holá vorbereiteten Repertorium erfasst; ihre Lebensläufe können dort nachgeschlagen werden. 
längst nicht der Fall. Nicht nur die privaten, persönlichen Bibliotheken, sondern auch die institutionellen sind meist kaum intakt geblieben, ja wohl überhaupt nicht erhalten. Bestenfalls sind diese Bestände in alle Winde zerstreut worden, wobei ihre Bücher darüber hinaus ihren „Geburtsschein“ („Heimatpass“) verloren haben. Für diese „Waisen“ suchen wir zwar intensiv ihr Zuhause, jedoch oft (ja meist) vergeblich, obwohl es zu den wichtigsten Voraussetzungen effektiver Arbeit und Interpretation unumgänglich zu gehören scheint zu wissen, wem die Bücher gehörten. Je größer der Abstand zu diesen Zeiten ist, desto mehr zerrinnen uns die relevanten Informationen über alte Provenienzen zwischen den Fingern. Weiter unten können wir das noch ganz konkret und anschaulich genug beobachten. Aber damit muss man sich schon versöhnen und auseinandersetzen und dies bei jeder konkreten Arbeit stets im Auge behalten.

Dem heute zur Verfügung stehenden gesamten Quellenzustand entspricht bis zu einem gewissen Grad auch das Rahmenniveau der Bearbeitung, die, obwohl unausgewogen, hohen Ansprüchen gerecht wird. Von den profilierten Forschernamen genügt es, Miriam Bohatcová, Josef Hejnic, Jan Martínek, Martin Holý und Lenka Veselá zu nennen, ${ }^{2}$ besonders dann das Großwerk von Petr Voit, der jedoch andere Wege geht. ${ }^{3}$ Im engeren dann sind František Šmahel ${ }^{4}$ und Jiř́ Pešek zu nennen. ${ }^{5}$ Auch zwei regionale Forschungszentren mit ihren bibliotheksgeschichtlichen Aktivitäten, meist frühneuzeitlich, steuern manches bei: Olmütz und Budweis. ${ }^{6}$

Die wichtigste Quelle sind stets die Handschriften und Drucke selbst, und als Wegweiser gelten ihre modernen Kataloge. ${ }^{7}$ Die zweite Quelle stellen alte Inventare von Einzelbibliotheken dar, die dritte dann das übrige sekundäre Material wie Korrespondenzen, Rechnungen

2 Das Lebenswerk M. Bohatcovás ist bibliographisch erfasst in Folia historica Bohemica 13, 1990, S. 513-523, mit Nachträgen in Sborník k 80. narozeninám Mirjam Bohatcové, Praha 1999. S. 375-378; das von Josef HEJNIC in seiner Festschrift Humanismus v rozmanitosti pohledi̊. Farrago festiva Josepho Hejnic nonagenario oblata [Der Humanismus in vielfältiger Sicht. Farrago festiva Josepho Hejnic nonagenario oblata], Praha 2014, S. 445-453. Eine Sammlung seiner Miszellen wäre wie im Falle der kleinen Schriften von Jan MARTíNEK, Martiniana. Studie o latinském humanismu v českých zemích [Martiniana. Studien zum lateinischen Humanismus in den böhmischen Ländern], Praha 2014, S. 471-483, willkommen. Ansonsten vgl. Lenka VesELÁ, Knihy na dvoře Rožmberků [Bücher am Hofe der Rosenberger], Praha 2005, und Martin HolÝ, Vzdělanostní mecenát v zemích České koruny [Das Bildungsmäzenatentum in den böhmischen Kronländern], Praha 2018, als partes pro toto.

3 Neben Dutzenden von literar-historischen bzw. buchgeschichtlichen Einzelstudien handelt es sich um folgende Trias: Encyklopedie knihy [Enzyklopädie des Buches], Praha 2013, Český knihtisk mezi pozdní gotikou a renesanci [Der böhmische Buchdruck zwischen Spätgotik und Renaissance], Praha 2015-2017, und Katalog prvotisků Strahovské knihovny v Praze [Katalog der Inkunabeln der Strahov-Bibliothek in Prag], Praha 2015, die rund 50 Inkunabeln universitärer Herkunft Ende des $18 \mathrm{Jh}$. käuflich erworben hat.

4 Seine diesbezüglichen Studien kommen im folgenden zu Worte.

5 Jiř́ PEŠEK, Měštanská vzdělanost a kultura v předbělohorských Čechách 1547-1620 (V̌̌ední dny kulturního života) [Die Bürgerliche Bildung und Kultur in Böhmen in der Zeit vor der Schlacht am Weißen Berg 1547-1620 (Der Alltag des kulturellen Lebens)], Praha 1993. Als unentbehrlich gilt auch der erste Band des vierbändigen Werkes Dějiny Univerzity Karlovy [Geschichte der Karlsuniversität], I, 1347/48-1622, unter der Redaktion von Michal Svatoš (Generalredaktion von František KavKa und Josef PetrÁŇ), Praha 1995, besonders der Beitrag von Jiří Pešek, der verschiedentlich mit dieser Thematik parallel läuft, ist in unserem Kontext wichtig.

6 Ersteres in der Reihe Bibliotheca antiqua, letzteres besonders durch die Reihe Opera romanica unter der Leitung von Jitka RADIMSKÁ.

7 Hier genügt es, auf den Band von Marie Tošnerová (Hg.), Guide to Manuscript Collections in the Czech Republic, Praha 2011, aufmerksam zu machen. Für die Inkunabeln und mehr noch für die Drucke des 16. Jahrhunderts (Paläotypen u. a. inbegriffen) gibt es nur ein paar Kataloge von Einzelbeständen. Neuerdings gewinnt das Projekt Monasterium immer mehr an Wichtigkeit. 
usw. Zu jeder der oben erwähnten Gruppe sind knappe einführende methodologische und quellenkundliche Bemerkungen nötig.

Zunächst zu den konkreten Überresten, d. h. zu den eigentlichen Büchern und ihrer mittelalterlichen und frühneuzeitlichen Provenienz, die festzustellen als primum necessarium gilt. Von Ausnahmen abgesehen, verwahren nämlich moderne Institutionen, die nicht immer unmittelbare Nachfolger mittelalterlicher und frühneuzeitlicher Besitzer sind, mittelalterliche und frühneuzeitliche Bücher. In jedem Fall gelten sie aber als Hauptvermittler nicht nur des ursprünglich institutionellen, sondern auch des privaten Buchgutes. Schon deshalb sind sie oft a priori - ja oft überhaupt - nicht imstande, ohne weiteres über die ursprüngliche, die alte Entstehungs- oder mindestens alte Hausadresse „unseres“ Buchgutes etwas auszuweisen. ${ }^{8}$ Doch muss man noch einen Schritt weiter gehen. Denn nirgendwo gilt automatisch, dass es sich auch in den Bibliotheken mit mittelalterlichem Eigenbestand nicht um frühneuzeitliche Zuwächse handelt.

Ein warnendes Beispiel ist die altehrwürdige Bibliothek des Prager Domkapitels, die was die Handschriften betrifft - zu den überhaupt wichtigsten in Tschechien gehört. Mit nur mäßiger Übertreibung ist nämlich zu sagen, dass in ihr bei weitem nicht alles (ja manchmal sogar die Mehrzahl nicht) von dem, was sich dort heutzutage befindet, sich schon im Mittelalter befunden hatte. Obwohl ihre wissenschaftliche Geschichte noch immer nicht geschrieben ist, ist zur wohl überzeugenden Illustration folgendes zu sagen: von den rund 1700 Handschriften (nur etliche Dutzende sind [früh]neuzeitlich) gelangte in den heutigen Bestand mindestens ein Viertel (möglicherweise sogar bedeutend mehr, da die Provenienzunterlagen allzu fragmentarisch sind) erst dank den Schenkungen der nachhussitischen, ja sogar frühneuzeitlichen Spender. Das gilt sehr oft auch dann, wenn es sich um Handschriften aus vorhussitischer Zeit handelt!

Und noch eines ist vorauszuschicken. Die Bibliotheken intellektueller Orientierung sind Einrichtungen spezifischer Art. Das gilt für die Universitätsangehörigen und ihre Kollegien doppelt; d. h., diese Bibliotheken enthalten, soweit ihre Besitzer nicht zugleich Bibliophile waren, liturgisches Gut nur in begrenztem Umfang, von illuminierten Handschriften ganz zu schweigen. Denn diese Bibliotheken waren ihrer Art nach ein aktuelles „Arbeitsinstrument" ihrer Inhaber und spiegeln ihre Stellung wider. Wo anders könnte man ope$r a$ von Kommilitonen, aber auch von Polemikern und Diskutanten finden als in solchen „Werkstuben“? Das bedeutet, dass solche Bibliotheken nicht selten ansonsten unbekannte oder wenigstes nicht allzu verbreitete aktuelle Texte beinhalten konnten, die in die innere und zugleich professionelle Welt ihrer Inhaber besser als sonst etwas anderes hineinzusehen erlauben. Dabei ist zugleich klar, dass hier deutlicher als sonst auch die regionalen bzw. persönlichen Spezifika zum Vorschein kommen konnten. ${ }^{9}$ Mit anderen Worten heißt das, dass man bei der handschriftlichen Inhaltsanalyse mehr als sonst mit Autographen bzw. Texten des Inhabers (und seiner Freunde) oder mit Kommentaren oder anderen autographischen Notizen rechnen kann. Nun, ein „Jammer“ freilich, wenn der Inhaber zugleich ein „Bücherwurm“ oder Bibliophile war (und genug Mittel besaß), der seiner Bibliothek die

8 Neuerdings sind verschiedene Projekte im Gange, die eben in etlichen großen Bibliotheken versuchen, den alten Provenienzen ihres Buchgutes nachzuspüren. Doch sind sie allgemeineren Charakters, weshalb sie sich mit dem Folgenden weder überschneiden noch berühren.

$9 \mathrm{Zu}$ dieser Problematik äußert sich innovativ Fritz Peter KnAPP, Grundlagen der europäischen Literatur des Mittelalters. Eine sozial-, kultur-, sprach-, ideen- und formgeschichtliche Einführung, Graz 2011. 
Grenzen einer einfachen Studienbibliothek zu überschreiten erlaubte. Bei den Drucken verhält sich das jedoch ein wenig anders. Eigene Drucke des Bibliotheksinhabers, d. h. durch ihn persönlich gedruckte eigene Werke, sind zwar die seltsamste Kategorie, doch ist auch diese in Prag belegt. Die Arbeit mit dem Buch, manchmal gar das Ringen mit dem Text, was sich in den scholia widerspiegelt, ist das Charakteristikum dieser Bibliothekskategorie und weckt mit Recht unsere Aufmerksamkeit. So etwas im folgenden Text anzubieten, ist freilich kaum zu erwarten, ja auch in Anspielungen nicht. Doch muss eine solche Analyse als pium desiderium gelten. ${ }^{10}$

Bei der Suche nach genaueren alten Provenienzen helfen auch verschiedene, vornehmlich alte Besitztumssymptome im weitesten Sinne des Wortes. Besonders sind das eindeutige Besitzervermerke, die jedoch an sich ein breites Spektrum möglicher bzw. weiterführender Indizien bieten. Der Bogen spannt sich von der Möglichkeit, den Erstbesitzer, ja den Schreiber bzw. die Datierung festzustellen (dazu dienen besonders die Kolophone, siehe dazu unten), bis hin zu den heutigen Besitzern. Das ist bei der intensiven Bücherzirkulation äußerst kompliziert, da sie an sich recht unterschiedliche Formen annehmen konnte, so besonders Kauf, Verschenkung, Tausch, Vererbung u. a. m., Diebstahl inbegriffen. Deshalb muss jeder Anklang an den alten (Ur)besitzer oder wenigstens Vorbesitzer genau analysiert werden, obwohl dies in längst nicht allen Fällen entsprechend aussagekräftig und eindeutig sein muss. Auch sehr zurückhaltende Analogien können dabei hilfreich erscheinen. Ähnliches gilt auch von anderen Symptomen individuellen Besitzes. Besonders ist darauf hinzuweisen, dass man seine Bücher auch mit Monogrammen bzw. Wappen gekennzeichnet hat, wenngleich wohl kaum systematisch. Aus der ersten Hälfte des 15. Jh. ist das für die Bibliothek Prokops von Pilsen ${ }^{11}$ belegt, Mitte des 15. Jh. dann für Wenzel Křižanovský12 und um 1500 für die Bibliothek Wenzel Korandas, der sogar mehrere graphische Formen seiner Initialen verwendete. ${ }^{13}$

Das bisher Gesagte betrifft die äußeren Merkmale, doch dürfen auch die inneren Merkmale in diesem Kontext nicht übersehen werden. Eindeutig am ergiebigsten ist ihre Kombination. Am wichtigsten sind dabei freilich die Schreiberkolophone, die - soweit sie deutlich genug sind - auch die (relativ) genaue Entstehungszeit bzw. den Entstehungsort mitteilen können. ${ }^{14}$ Schon hier ist zu sagen, dass im Kontext der Prager Universität ein deutliches Beispiel angeführt werden kann. Es handelt sich um den engen Gefährten Johannes

10 Die Literatur, die sich diesen Fragen widmet, ist umfangreich, doch sei nur das Wichtigste erwähnt, so besonders das Großprojekt von Giovanna MuRAno in Zusammenarbeit mit Giovanna MoRelli, Autographa, Bologna 2012ff. Im Rahmen der böhmischen Problematik ist besonders an die Arbeiten von Marie Bláhová, Zdeňka Hledíková und Běla Marani-Moravová über die Schreibarbeit Peters von Zittau im vatikanischen Autograph seiner Chronik zu erinnern. Letztgenannte resümiert die Erträge dieser Arbeiten in ihrer Dissertation Peter von Zittau. Abt, Diplomat und Chronist der Luxemburger, Ostfildern 2019.

11 Vgl. Jaroslav Prokeš, M. Prokop z Plzně, Praha 1927, S. 142 und besonders S. 235, Anm. 613, wo man sich auch über den Streit um seine Bibliothek zwischen der Universität und dem Prager Metropolitankapitel belehren lassen kann.

12 Vgl. Eva GrEgorovičová, Soukromé knihovny mistrů kolem pražského vysokého učení v pohusitském obdobi [Privatbibliotheken der Magister an der Prager Hohen Schule in nachhussitischer Zeit], maschinenschriftliche Diplomarbeit an der Philosophischen Fakultät der Karlsuniversität, Prag 1975, S. 62-118. Bei Křižanovský handelt es sich um ein einziges nicht publiziertes, aber kaum überholtes Kapitel. Sonst handelt es sich um Stanislaus von Welwarn, Stanislaus von Gnesen, über deren Bibliotheken sie Jahre später selbständige Aufsätze publizierte (vgl. Anm. 52). Zu Wenzel Koranda vgl. die neue Monographie von J. Marek hier in Anm. 47.

13 Siehe unten.

14 Vgl. Bénédictins du Bouveret Colophons des manuscrits occidentaux, I-VI, Fribourg 1965-1982. 
Rokycanas, Peter von Dvekačovice, dessen Bibliothek wohl dem Karlskolleg geschenkt worden war. Leider deklarieren sich nur sechs Handschriften deutlich als Peters ursprüngliches Eigentum. Da sie jedoch inhaltlich breit gefächert sind, muss man voraussetzen, dass sie eine bedeutend große Bibliothek signalisieren. ${ }^{15}$ Leider sind solche Kolophone nicht so häufig, wie man sich wünschen möchte. Als ein allgemein willkommenes praktisches Hilfsmittel bei Provenienzidentifikationen ist das „Manual“ des Engländers N. R. Ker in seinem Buch über englische Handschriften des Mittelalters zu empfehlen. ${ }^{16}$

Ein weiterer wichtiger, ja unersetzlicher Helfer bei bibliotheksgeschichtlichen Forschungen sind verschiedene alte Bücherverzeichnisse. ${ }^{17}$ Was ihre Aussagekraft betrifft, so variiert sie sehr: von Lapidarität, die nur wenig hilft, bis zur Ausführlichkeit gar mit Provenienzund Vorlagenangaben bzw. Incipits und Explicits, die imstande sind, auf Grund solcher Angaben erhaltene Kodizes ziemlich leicht zu identifizieren. Das wiederum ist jedoch nur selten der Fall. Normalerweise sind aber die Hürden für derart breiter gefasste Vergleichsforschungen mitunter fast unüberwindbar. Überdies besitzen wir solche Unterlagen oft über Bibliotheken der am Rande stehenden Leute und Institutionen, die kaum etwas Nennenswertes verraten (da sie z.B. nur liturgisches Gut aufweisen können). Andererseits vermissen wir sie jedoch bei bedeutenden Leuten und Institutionen, wo sie erfolgreich sein können. Auch Unterschiede zwischen „persönlich“ und ,institutionell“" sind von Bedeutung. Dafür nur zwei kleine institutionelle Beispiele. Das erste ist zwar einer anderen sozialen Gruppe entnommen, ist jedoch besonders anschaulich, da von allgemeinerer Geltung.

Aus der zweiten Hälfte des 14. Jh. sind etliche Mobilieninventare des Prager Metropolitankapitels erhalten, ${ }^{18}$ worin auch Bücher vorkommen. Das umfangreichste Inventar führt rund 250 Titel an. Dabei kann man jedoch nur einen kleinen Bruchteil seiner Einträge mit konkreten Handschriften in situ wenigstens mit gewisser Wahrscheinlichkeit identifizieren. Das zweite Beispiel bringt uns unserem Thema näher, doch mit noch magererem Ergebnis. Das Prager universitäre Karlskolleg besitzt aus den 70er Jahren des 14. Jh. einen Lokationskatalog, ${ }^{19}$ eher -inventar, mit knapp 210 Kodizes, wobei ebenfalls nur ganz vereinzelte Handschriften mit dem heute erhaltenen Gut identifiziert werden können. Und dabei gilt es, dass beide Institutionen zwar ein sozusagen ununterbrochenes Dasein aufweisen, obwohl in beiden Fällen ihre Wege samt den Büchern nicht geradlinig verliefen. Im universitären Fall fiel das ganze Hab und Gut, Bücher inbegriffen, der utraquistischen Universität und im Dreißigjährigen Krieg dann übergangslos den Prager Jesuiten in den Schoss. Nach Aufhebung des Ordens in der josephinischen Zeit wurden jedoch ihre dezimierten Überreste

15 Vgl. František M. BARToš, Bojovníci a státníci husitští a Universita Karlova [Hussitische Kämpfer und Staatsmänner und die Karlsuniversität], Historia Universitatis Carolinae Pragensis (weiter HUCP) 12, 1972, S. 32-36.

16 Vgl. Neil R. Ker, Medieval Libraries of Great Britain, London 1960. Nützlich sein kann neuerdings auch das Buch von Michal Dragoun, Středověké rukopisy v českých zemích. Handbušek kodikologa [Mittelalterliche Handschriften in den böhmischen Ländern. Handbüchlein des Kodikologen], Praha 2018.

17 Allgemeine Belehrung bringt Albert Derolez, Les catalogues de bibliothèques (Typologie des sources du moyen âge occidental 31), Turnhout 1979. Vgl. konkret für das böhmische Königreich Ivan HLAVÁČEK, Středověké soupisy knih a knihoven v českých zemích [Mittelalterliche Bücher- und Bibliotheksverzeichnisse in den böhmischen Ländern], Praha 1965. Wegen etlicher Neufunde ist das Buch heutzutage ergänzungsbedürftig. Wichtig und von Interesse können auch die Nachlassinventare - Testamente sein; in dem uns betreffenden Fall gilt das jedoch kaum. Vgl. sonst Thomas KRZENCK, Böhmische Bürgertestamente des 15. Jahrhunderts, Marburg 2017.

18 Vgl. I. HLAVÁČEK, Středověké soupisy, Nr. 92.

19 Siehe Anm. 22. 
auch weiterhin zum Teil zerstreut und verschleudert. Die Mehrzahl des übriggebliebenen Buchgutes wurde dann zum Grundstock der damals (1777) gegründeten Prager Universitätsbibliothek (heute Nationalbibliothek). ${ }^{20}$

Nichtsdestoweniger handelt es sich in der obengenannten Bibliothek heutzutage nur um ziemlich dürftige, jedoch wichtige Überreste der mittelalterlichen und frühneuzeitlichen Schätze der alten Carolina, deren Großteil ihre Kollegienbibliotheken darstellen, die das erhaltene, meist anonyme Gut der Magister aufbewahren. ${ }^{21}$ Aber ein glücklicher Zufall erlaubt uns, doch tiefer in die Zusammensetzung des posthussitischen universitären handschriftlichen Buchgutes zu blicken. Es existieren nämlich umfassende Bücherkataloge zweier Universitätskollegien: des Kollegs der böhmischen Nation und des in nachhussitischer Zeit gegründeten Reček-Kollegs (1438), beide Kataloge aus dem dritten Viertel des 15 . Jh., die jüngst vorbildlich ediert und kommentiert wurden. ${ }^{22}$ Und schließlich muss das relativ späte (1603) und wortkarge Bibliotheksinventar des mit dem Karlskolleg gleichaltrigen (1366) Allerheiligenkollegs erwähnt werden. Das nämlich beinhaltet darüber hinaus das Inventar der Privatbibliothek seines Propstes Johann Adam Bistřický von Buchau (dreifacher Rektor der Carolina) mit genau 106 Büchern. ${ }^{23}$ Dieser Bibliothek sowie den wenigen erhaltenen Inventaren von Magisterbibliotheken gilt noch unten unsere ausführlichere Aufmerksamkeit. ${ }^{24}$ Von der Existenz des wohl wichtigen Übernahmekatalogs des Karlskollegs durch die Jesuiten aus dem Jahre 1622 wissen wir leider nur aus einer Notiz aus zweiter Hand. ${ }^{25}$

Die dritte Kategorie bilden schließlich Quellen sekundären Charakters. Obwohl sie meist nur subsidiär sind, trifft das in unserem Falle eben nicht zu. Denn wir besitzen zwei außerordentlich qualitätsvolle Quellen. Zum einen ist das die Korrespondenz Kaspar Nydbrucks, eines namhaften reichsadeligen evangelischen Bibliophilen, mit seinen Prager Freunden aus der Mitte des 16. Jh., in der eben Bücher im Zentrum des Interesses stehen. ${ }^{26}$ Kaspar

20 Dazu Zdeněk Tobolka, Národní a universitni knihovna v Praze, její vznik a vývoj, I, Počátky knihovny až do r. 1777 [Die National- und Universitätsbibliothek in Prag, ihre Entstehung und Entwicklung, I, Die Anfänge der Bibliothek bis 1777], Praha 1959, passim.

21 Dieses Gut wurde in wichtigen Handschriftenkatalogen von Josef TruHLÁŘ verzeichnet: Catalogus codicum manscriptorum qui in c. r. bibliotheca publica ac universitatis Pragensis asservantur, I-II, Pragae 1905-1906, und Ders., Katalog českých rukopisủ c. k. Veřejné universitní knihovny pražské [Katalog der tschechischen Handschriften der k. k. Öffentlichen Prager Universitätsbibliothek], Praha 1906. Ein Verzeichnis des deutschsprachigen Gutes bringt Walter Dolch, Katalog der deutschen Handschriften der Universitätsbibliothek in Prag, I, Prag 1909, das aber unergiebig ist.

22 Zuzana Silagiová - František Šmahel, Catalogi librorum vetustissimi Universitatis Pragensis. Die ältesten Bücherkataloge der Prager Universität (Corpus Christianorum Continuatio mediaevalis 271, Magistri Iohannis Hus Opera omnia XXXVIIB, Suplementum II), Turnhout 2015, wo sich auch die neueste Edition des vorhussitischen Katalogs des Karlskollegs befindet.

23 Ediert von Josef Teige, Základy starého místopisu pražského [Grundlagen der alten Prager Topographie], I/2, Praha 1915, S. 191-193, davor von Zikmund WINTER, O životě na vysokých školách pražských knihy dvoje [Zwei Bücher über das Leben an den Prager Hochschulen], Praha 1899, S. 177, zum guten Teil paraphrasiert.

24 Vgl. auch Ivan HLAvÁČEK, Knihovna koleje Všech svatých v r. 1603 na základě svého soupisu. Př́spévek k dějinám knihoven pražské univerzity v 16. stoleti [Die Bibliothek des Allerheiligenkollegs 1603 anhand ihres Verzeichnisses. Beitrag zur Geschichte der Bibliotheken der Prager Universität im 16. Jahrhundert], in: Zdeňka Hledíková (ed.), Traditio et cultus. Miscellanea historica Bohemica Miloslao Vlk archiepiscopo Pragensi ab eius collegis amicisque ad annum sexagesimum dedicata, Praha 1993, S. 119-127.

25 Vgl. Antonín HaAs, Archiv Karlovy university v Praze [Das Archiv der Karlsuniversität in Prag], Časopis archivní školy 15-16, 1937-1938, S. 50; 1945 fiel es leider nazistischer Wut zum Opfer.

26 Ediert von Ferdinand Menčí , Dopisy M. Matouše Kollina z Chotěřny a jeho přátel ke Kašparovi z Nydbrucka, tajnému radovi krále Maximiliána II. [Briefe von M. Matthaeus Collinus von Chotěrina und seiner Freunde an 
engagierte sich aus eigener Vorliebe, jedoch noch mehr als Vermittler, für Flacius Illyricus $(† 1575)$ und sein reformatorisches Editionsvorhaben. Kaspars Freunde rekrutierten sich zum guten Teil aus dem Umkreis der Prager Universität. Da diese Korrespondenz so gut wie stets die Texte der böhmischen Reformation, deren Dokumentation Kaspar besonders am Herzen lag, und oft die Universität und ihre Glieder direkt betraf, ist sie wichtig. Die Bücher, rund 50 an der Zahl, die er für Flacius ausgeliehen hatte, verfielen nach Kaspars Tod bei Hofe an den Kaiser und gelangten auf Umwegen schließlich in die Wiener Nationalbibliothek.

Die zweite Quelle dieser Art spricht uns noch unmittelbarer an und wird zu einer der wichtigsten Unterlagen der folgenden Darstellung überhaupt. Der vor der Einverleibung der gesamten Universität in die jesuitische Akademie letzte Vorstand des Karlskollegs, Magister Johannes Kampanus Vodňanský, hat nämlich 1615 sein Calendarium beneficiorum Academiae Pragensis collatorum drucken lassen. ${ }^{27}$ Dort verzeichnete er aufgrund verschiedener, meist nicht mehr erhaltener Unterlagen Einzelspenden, aber auch fromme Vermächtnisse und Stiftungen vornehmlich seitens der Universitätsangehörigen. Dabei ist jedoch klar, dass man dort noch längst nicht alles, was gestiftet worden war, eingetragen hatte. ${ }^{28}$ Und wenn schon Kampanus Konkretes festhält, dann äußert er sich fast stets nur ganz unbestimmt und wortkarg. Die Antwort auf die Frage, was die Kollegiaten spenden konnten, liegt auf der Hand: Bücher, obwohl gelegentlich auch Geld und Immobilien in Frage kamen, einmal sogar eine Druckereiausstattung.

Um die folgenden Ausführungen übersichtlicher zu gestalten, ist es nützlich, ganz grob zu periodisieren. Die erste Etappe reicht bis 1420, die zweite endet mit dem Jahr 1526 (Wechsel der Dynastien und Aufmarsch der Habsburger), die letzte dann endet mit dem Untergang der alten Carolina. Man würde meinen, dass noch eine gewisse Trennungslinie innerhalb der Quellengattung „Professorenbiblotheken“ zu ziehen ist (zwischen den vornehmen und den durchschnittlichen Magistern). Doch dies scheint gefährlich zu sein, denn Professoren ohne literarische Tätigkeit konnten ebenso zu den „Bücherwürmern“ gerechnet werden wie die literarisch aktiven, die neben Texten zu Unterricht bzw. „Forschung“ jedoch noch eigene opera verwahrten, obwohl diese fast ausnahmslos nur in Abschriften, sogar oft mit zeitlichem, mitunter größerem Abstand erhalten geblieben sind. Und sollte es sich um Polemisches handeln, dann kümmerten sie sich auch sicherlich nicht nur um Werke ihrer Widersacher, sondern ebenfalls darum, dass die eigenen Produkte möglichst breite Publizität bekämen. ${ }^{29}$ Die zur Arbeit nötigen Autoritäten konnten sie sich zwar auch aus den Kollegienbibliotheken leihen, doch die wichtigsten Titel besaßen sie sicher privat. Übrigens weiss

Casparus von Nydbruck, Geheimrat König Maximilians II.], Praha 1914. Vgl. dazu auch das wichtige Referat von Kamil Krofta in: Český časopis historický 22, 1916, S. 458-465.

27 Vgl. die Edition von Karel Hrdina, Mistr Jan Kampanus, Mecenáši Karlovy university [Magister Johannes Kampanus, Mäzene der Karlsuniversität], Praha 1949, und eine jüngere Edition, die Hrdinas Edition nicht kennt, von Josef PolišEnsKÝ - Jana VoBráTILOvÁ, M. Jana Kampána Kalendár̆ dobrodiní prokázaných pražské univerzitě [Des Magisters Johannes Kampanus Kalender der Prager Universität erwiesener Wohltaten], HUCP 4/1, 1963, S. 67-95. Ich arbeite vornehmlich mit Hrdinas Text, obwohl sich beide Kommentare in gewissem Sinne verschiedentlich ergänzen.

28 Nur aus den 60er Jahren des 15. Jh. sind zufälligerweise zwei relativ umfangreiche Büchervermächtnisse von Universitätsangehörigen in das Registrum Rečeks eingetragen worden, worüber noch ausführlicher unten.

29 Da ist auf das Kompendium von Pavel SpUNAR hinzuweisen: Repertorium auctorum Bohemorum provectum idearum, I-II, Wratislaviae 1985, resp. Warsawiae - Pragae 1995 (bis cca 1434). Für die Zeit danach knüpft ebenfalls Pavel SPUNAR mit seinem Aufsatz Literární činnost utrakvistů doby poděbradské a jagellonské [Die 
man, dass die Magister manchmal ermahnt worden sind, Dutzende aus den Kollegienbibliotheken geliehene Bände zurückzugeben, die sie lange Zeiten buchstäblich blockierten.

Wenn wir die nicht eben zahlreichen Spender außerhalb der Universität beiseitelassen, die nur selten zu Büchern griffen, so sind es im Falle von Kampanus für die vorhussitische Zeit knapp 17 Spender, die bis zum Ausbruch der hussitischen Revolution Bücher teilweise geschenkt, teilweise vermacht haben. Es handelte sich dabei um Einzelbände (falls es Pergamente waren, dann hat das Kampanus vermerkt), meist mit nur ganz grober inhaltlicher Charakteristik; als größten Spender aus vorhussitischer Zeit kann man aus Universitätskreisen den Theologieprofessor und Gönner des jungen Hus, Johann Wenzel von Prag ( $\dagger$ vor 1400) nennen, der dem Kolleg Nationis plurimos libros, wohl meist theologische Bücher schenkte. Leider notiert Kampanus sowohl bei dieser als auch bei anderen größeren Stiftungen weder die genaue Zahl der geschenkten Bücher noch ihre inhaltlichen Profile, was er zwar auch, aber nur ausnahmsweise und in groben Umrissen macht. In einem solchen Fall kamen dann so gut wie alle Zweige der damaligen universitären Wissenschaften vor: von der Medizin über Philosophie, kanonisches Recht bis zu den Artes liberales und zur Theologie, ja auch zu den römischen Klassikern. ${ }^{30}$ Liturgisches und Andachtsgut, sonst anderswo so häufig, kommt hier und eher noch in den nachfolgenden Zeiten fast so gut wie kaum vor.

Die meisten Spenden zielten überraschenderweise nicht, wie man vermuten möchte, in das große, also das Karlskolleg, sondern ins collegium Nationis, das heißt in das Kolleg der böhmischen Nation. Jedoch nicht immer profitierte die Prager Alma Mater von den privaten Büchern ihrer Mitglieder. Mitunter erzählt der eine oder andere Kodex eine andere, fast abenteuerliche Geschichte. Man braucht hier nur an den Prager Mediziner Sulko von Hoštka zu erinnern, dessen zwei Bücher, die sich sicher aus (wohl bedeutend) größerem, sonst verlorenem Bestand erhalten haben, über ein spannendes, jedoch nicht näher verfolgbares Schicksal erzählen. Ein Kodex des 12. Jh. mit ciceronianischen Texten, wohl aus Corvey stammend, fand Zuflucht an der Erfurter Universität (ist heutzutage jedoch in Berlin), ein anderes Werk (ein dreibändiger Avicenna, eine professionelle Arbeit des berühmten Bücherschreibers Martin Korček) landete in unbekannter Weise über die Mainzer Dombibliothek in der Würzburger Universitätsbibliothek. ${ }^{31} \mathrm{Da}$ ist auf ein Phänomen hinzuweisen, dass infolge zweier Auszüge aus der Universität (nach 1409 und dann um die Mitte des 15. Jh.) eine nicht unerhebliche Menge an Büchern ins Ausland gekommen ist. Ein freilich enigmatisches Paradebeispiel ist eine Handschriftengruppe, die mit der Prager Universität unmittelbar zusammenhängt und heute in der Parker Library im Corpus Christi College in Cambridge aufbewahrt wird. ${ }^{32}$

literarische Tätigkeit der Utraquisten zu Zeiten Podiebrads und Jagiellos], in: Acta reformationem Bohemicam illustrantia 3, Praha 1978, S. 165-260 an.

30 Darüber im breiteren Kontext Miroslav Flodr, Die griechische und römische Literatur in tschechischen Bibliotheken des Mittelalters und der Renaissance, Brno 1966, besonders S. $93 \mathrm{ff}$.

31 Vgl. František ŠMAHeL, Mistři a studenti pražské lékařské fakulty do roku 1419 [Magister und Studenten der Prager medizinischen Fakultät bis 1419], HUCP 20/2, 1980, S. 35-68, hier S. 63, Nr. 93, und Paul LehmanN, Erforschung des Mittelalters V, Stuttgart 1962, S. 131f. Die handschriftlichen Informationen sind nicht eindeutig, ja eher kontrovers. Doch kann man ihn für 1410 kaum als Prager Rektor bezeichnen, wie es in Dějiny Univerzity Karlovy, I, S. 199, zu lesen ist. Übrigens finden wir seinen Namen schon in den Rektorenlisten: ibidem, S. 291f., gar nicht.

32 Vgl. Jiří KeJŘ, Díla pražských mistrů v rukopisech knihovny Corpus Christi College, Cambridge [Werke der Prager Magister in den Handschriften der Bibliothek des Corpus Christi College, Cambridge], in: Ders., Výbor rozprav a studií z kodikologie a právních dějin, Praha 2012, S. 299-334. 
Auch in der hussitischen und nachhussitischen Zeit gibt es, ein wenig überraschend, ziemlich häufige Spenden und Spender. Buchstäblich inmitten der Revolutionswirren erfolgte 1424 eine Spende biblischer Konkordanzen von dem sonst unbekannten Magister Martin Lapka von Prostiboř. Irgendwann in der Übergangszeit, d. h. nach 1436, erhielt die Universität - ein bisschen überraschend - wohl das größte Donum der Zeit. Es kam von ihrem ehemaligen Rektor (1410), der zugleich Leibarzt des Königs und willkommener Gast am Königshof war: dem Prälaten Johann Schindel († nach 1455), der dem Karlskolleg über zweihundert Bücher, meist medizinischen und mathematischen Inhalts, geschenkt hatte. ${ }^{33}$ Sollte die Zuschreibung Urbánkovás einer von ihr rekonstruierten Handschriftengruppe richtig sein - und es sieht wahrscheinlich so aus -, dann haben wir nicht nur einen Arzt, Mathematiker und Astronomen vor uns, sondern auch einen fleißigen Handschriftensammler. Denn in diesem zufällig erhaltenen Torso gibt es mehrere Handschriften sogar des 12. und 13. Jahrhunderts, die neben der „Fachliteratur“ der Zeit auch Klassiker wie Cicero, Statius oder Horatius beinhalten.

Aus der Zeit der hussitischen Revolution haben wir auch eine ziemlich kuriose und zweifelsfrei einzigartige Nachricht: Johannes Rokycana kaufte als Mitglied des Kollegs Nationis im Juni 1434 Bücher für sein Kolleg. Aber wo! Auf Karlstein, dem wichtigsten Bollwerk der Katholiken in Mittelböhmen. Leider ist die Nachricht allzu dürr, so dass wir nichts Konkreteres wissen und nur vermuten können, dass es sich um Bücher entweder des Prager oder des Karlsteiner Kapitels handelte bzw. etlicher Klöster, die auf Karlstein ihre Schätze beherbergten. ${ }^{34}$

Johannes Rokycanas $(\dagger 1471)$ monumentale Gestalt, wohl eine der wichtigsten des 15. Jh., verdient auch sonst nähere Aufmerksamkeit. Seine politischen, besonders kirchenpolitischen Aktivitäten interessieren hier jedoch nicht, da ihnen in jedem Werk über die böhmische Geschichte jener Zeit Aufmerksamkeit zuteil wird. ${ }^{35}$ Dasselbe gilt auch hinsichtlich seiner sicher umfangreichen intellektuellen, besonders dann literarischen Arbeit (auch in tschechischer Sprache), die mit seiner nicht erhaltenen Bibliothek (möglicherweise befinden sich etliche Bände anonym unter den Resten der ursprünglichen mittelalterlichen Bestände der Nationalbibliothek Prag) sicher eng zusammenhing. Die älteste konkrete Nachricht über Bücher, die sich im Zusammenhang mit Rokycana erhalten hat, stammt aus dem Jahre 1427, als ihm zwei von einem gewissen Wenzel Wachsbleicher

33 Vgl. Emma UrbánKová, Zbytky knihovny snad M. J. Šindela v Universitní knihovně [Reste der Bibliothek wohl des Magisters J. Šindel in der Universitätsbibliothek], in: Ročenka Universitní knihovny v Praze 1960-1961, Praha 1962, S. 87-97. Vgl. Mistr Jan Kampanus, Mecenáši, S. 14 und 59 mit weiteren Literaturhinweisen, und P. SpUnAR, Repertorium, I, S. $133 \mathrm{ff}$.

34 Josef Pelikán (Hg.), Účty hradu Karlštejna z let 1423-1434 [Rechnungen der Burg Karlstein aus den Jahren 1423-1434], Praha 1948, S. 161.

35 Von den enzyklopädischen Stichworten seien lediglich der Lexikonartikel in: Lexikon české literatury. Osob-

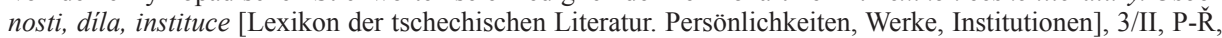
Praha 2000, S. 1268f., und besonders zwei Referenzwerke angeführt: F. M. BARToš, Literární činnost M. Jana Rokycany, M. Jana Př́brama, M. Petra Payna [Die literarische Tätigkeit der Magister Johannes Rokycana, Johannes Př́bram, Peter Payne], Praha 1928, S. 19-51, der rund 50 bibliographische Einheiten von Rokycanas Werken sowohl tschechisch als auch lateinisch verzeichnet, und Pavel SpunAR, Repertorium, II, dem Register zufolge. Besonders hinzuweisen ist auf den dortigen Index codicum, dem zu entnehmen ist, dass das meiste des reformatorischen Gutes, soweit in den Handschriften auf uns gekommen, sich dennoch in klösterlichen Bibliotheken, also bei den Widersachern erhalten hat. 
(voštník, ceraefusor) ${ }^{36}$ ausgeliehene Bücher unbekannten Inhalts testamentarisch vermacht wurden. ${ }^{37}$ Daraus ergibt sich, dass die Prager Universitätsmitglieder rege Kontakte mit dem dortigen Bürgertum und ihrer Verwaltung pflegten, was andererseits etwas über das kulturelle Niveau der Prager Bevölkerung aussagt.

Übrigens hatte Rokycanas Privatbibliothek mehrere Dutzend Bände beinhalten müssen, obwohl er neben den Kollegienbibliotheken auch die Bibliothek der Teynkirche in der Prager Altstadt als ihr Pfarrer benutzen konnte. ${ }^{38}$ Man rechne: seine tschechische Postilla ist in 11 Hss. erhalten. Zwar stammen sie zumeist aus dem späten 16. und 17. Jh., mussten aber mehrere Vorlagen des 15. Jahrhunderts gehabt haben, die bis zu Rokycanas Privatbibliothek führen müssen. Dabei taucht auch die Frage auf, wie es mit der Vervielfältigung von Rokycanas und auch anderer Magister Werken aussah. ${ }^{39}$ Über die Herkunft der Kopisten, die sich ums Abschreiben bei Rokycana und auch anderswo darum bemühten, wissen wir zwar nichts, können jedoch vermuten, dass es sich überwiegend um Mitglieder der Universität handelte (vermutlich um vornehmlich etliche Bursarii, eventuell für ein Entgeld). Die Autoren selber taten das kaum, und wenn schon, dann sicher nur ausnahmsweise; auch galten sie als Korrektoren der Texte. Mehrere Schreibervermerke in der Art der reportata in collegio oder ähnlich sind sicher im obgenannten Sinne zu interpretieren.

Eine Episode ist hier zu erwähnen. Man weiß nämlich, dass Delegate des Basler Konzils in Prag während ihres Besuches Anfang der 30er Jahre vorteilhaft Bücher einkauften. Fast mit Sicherheit handelte es sich dabei um das Buchgut, das mittel- bzw. wohl eher unmittelbar aus den Prager Kollegienbibliotheken stammte und Anfang der 20er Jahre während der Volkstumulte nach dem Tode Želivskýs besonders aus dem Karolinum entwendet worden war, was eine der Möglichkeiten für die weitläufige Peregrination des ursprünglichen Buchgutes der Prager Magister sein konnte. ${ }^{40}$

Im hussitischen Jahrhundert flossen Büchergeschenke in den kriegerischen Jahren freilich sporadisch, doch sah dies nach einer gewissen Beruhigung der Verhältnisse ab Ende der dreißiger Jahre bedeutend erfreulicher aus. Zunächst sind hier drei bzw. vier außerordentliche Gaben, chronologisch geordnet, vorzustellen. Die beiden ersten Großspenden bildeten ganze Bibliotheken, die an den hussitischen Kollegienneugründungen $a b$ ovo entstanden. Die erste Bibliothek wurde von Johannes Reček ins Leben gerufen (1438). In seiner Gründungsurkunde wurden zwar weder Bibliothek noch Bücher erwähnt, jedoch hat man eine andere hochwichtige Quelle zur Verfügung, die die Situation in ein bedeutend klareres Licht stellt. Es handelt sich um den schon erwähnten Bücherkatalog des Kollegs aus der Zeit um 1460.41 $\mathrm{Ihm}$ zufolge besaß diese Bibliothek nach ihrer Existenz von einem

36 Es handelte sich um wohl gut betuchte Bürger der Prager Altstadt: V. V. Toмeк, Základy starého mistopisu pražského. Registř̌k jmen osobních [Grundlagen der alten Prager Topographie. Register der Personennamen], Praha 1875, dem Register zufolge, S. 168 b.

37 Siehe V. V. Tomeк, Dějepis města Prahy [Geschichte der Stadt Prag], IX, Praha 1893, S. 251.

38 Eine erste konkrete Nachricht darüber stammt aus dem Jahre 1380. Damals besaß die Bibliothek unter den 29 Handschriften überwiegend Liturgica. Vgl. I. HLAVÁČEK, Středověké soupisy knih a knihoven, S. 116.

39 Es genügt, die Referenzwerke von F. M. BARTOŠ, Literární činnost, und von P. SPUNAR, Literárni činnost, zur Hand zu nehmen.

40 Vgl. Hildegund HöLzeL, Heinrich Toke und der Wolfenbütteler „, Rapularius “ (Studien und Texte der MGH 23), Wiesbaden 1998, S. $58 \mathrm{ff}$

41 Z. Silagiová - F. Šmahel, Catalogi, S. 11-57. Der zweite erhaltene Katalog aus dieser Zeit, der dem alten Kolleg Nationis angehört, wies freilich bedeutend mehr Bände auf, gegenüber den kaum 800 Bänden des Reček-Kollegs ursprünglich fast das Doppelte. 
knappen Jahrhundertviertel schon kaum vorstellbare 800 Bände! Über das zweite Kolleg, das von dem hussitischen Hauptmann Matthias Louda von Chlumčany (1451) gegründet wurde, haben wir keine derartige Quelle. Kampanus zufolge handelte es sich nicht nur um das nach ihm benannte Kolleg, sondern ausdrücklich auch um eine Stiftung seiner Bibliothek. ${ }^{42}$ Woher nun konnten die Bücher in den beiden Bibliotheken in solchen Unmengen herrühren? Da der Buchhandel nicht eben allzu rege war (möglicherweise unterschätzen wir ihn aber) und die Gelder auch nicht immer in entsprechendem Umfang vorhanden waren, ist das Resultat leicht zu fassen. Als Hauptquelle galten in beiden Fällen sicher die Magisterbibliotheken, obwohl wir nur ganz grobe Nachrichten in dieser Richtung besitzen. Die schon erwähnten Editoren der Kollegienkataloge sind darüber hinaus der Meinung, dass dabei auch der Bücherfundus der inzwischen aufgehobenen Kollegien der Juristen bzw. Mediziner im Spiel war. ${ }^{43}$ Denn wie anders könnte man sich erklären, dass sich in Rečeks Katalog eine ziemlich große Zahl von Multiplikaten befindet? Nur zur Illustration genügt es, mehrere Exemplare der Statuten Ernsts von Pardubitz ${ }^{44}$ anzuführen, doch fänden sich auch weitere Beispiele. Das Schlagendste liefert aber Rečeks Katalog selbst. Denn dort finden sich, sozusagen nur am Rande, zwei Büchernachlässe aus dem Jahre 1463 notiert. Bei ersterem handelt es sich um einen gemeinsamen Nachlass von 17 Texten/Kodizes zweier ehemaliger Kollegiaten: des Matthias von Prosenice und des Nikolaus von Choceň, die beide am Reček-Kolleg studierten. Und die zweite Liste galt dem Nachlass von 13 Bänden eines Matthias von Hohenmaut. Der erste Nachlass beinhaltet überwiegend philosophische, der zweite auch grammatikalische Literatur. Im ersten Fall fasziniert darüber hinaus ein Gesangbuch (Kantional) mit französischen Liedern, das leider verschollen ist. Zusammenfassend ist zu sagen, dass die Anzahl der in das Reček-Kolleg meist dank Spenden und Nachlässen der Kollegienmagister und wohl auch dank der Teilübernahme des Erbes der aufgehobenen Kollegien gelangten Kodizes imposant ist. Die Magisternamen sind von Zeit zu Zeit bekannt, die konkreten Titel hingegen können den einzelnen Stiftern nur selten zugewiesen werden. ${ }^{45}$

Die - mit Ausnahme der italienischen „Beute“ - inhaltlich nicht allzu interessanten Überreste von Křižanovskýs Bibliothek verdienen vornehmlich unter einem anderen Aspekt unsere Aufmerksamkeit. Křižanovský war zunächst Utraquist, konvertierte jedoch zum Katholizismus und wurde deshalb nach Streitigkeiten, die die Universität mit dem Metropolitankapitel auch um den Büchernachlass Prokops von Pilsen hatte, aus der Universität ausgeschlossen. Anschließend avancierte er im Prager Domkapitel und kam auch anderswo zu mehreren Pfründen und wurde zum heftigen antihussitischen Polemiker. Deshalb sind 10 seiner heute in der Prager Kapitelbibliothek erhaltenen Bände wohl nur ein Teil einer einst umfangreicheren Bibliothek. Zum Teil eindeutige Autographen bezeugen seinen Aufenthalt in Italien, wo er mehrere antike Klassiker abschrieb, die griechischen dann in

42 Mistr Jan Kampanus, Mecenáši, S. 15, und Michal Svatoš, Jan Reček a jeho písemná pozůstalost v archivu pražské univerzity [Johannes Reček und sein schriftlicher Nachlass im Archiv der Prager Universität], HUCP 14, 1974, S. 121-160; Ders., Listiny k počátkům koleje Matyáše Loudy z Chlumčan [Urkunden zu den Anfängen des Matthias-Louda-von-Chlumčany-Kollegs], ibidem 17/1, 1977, S. 71-96.

43 Z. Silagiová - F. Šmahel, Catalogi, S. XLIII. Sie denken jedoch vornehmlich an das Collegium Nationis, doch konnten auch diese Stiftungen irgendwie davon profitieren.

44 Z. Silagiová - F. Šmahel, Catalogi, S. 28, bzw. im Index S. 278.

45 So auch Z. Silagiová - F. Šmahel, Catalogi, S. XXVIIff. und XXXIXf. mit dem Versuch, die jährlichen Zugangsraten zu rekonstruieren. 
modernen Übersetzungen italienischer Humanisten (Bruni von Arezzo), jedoch auch Scholastiker; der Rest wurde meist durch Kauf oder Tausch erworben. ${ }^{46}$

Außer dem Legat wohl des Johannes Šindel ist nun noch die imposante Gabe des Wenzel Koranda d. J. († 1519) zu erwähnen, die neuerdings inhaltlich vorbildlich durch Jindřich Marek $^{47}$ analysiert und in die allgemeineren Bibliotheksverhältnisse Böhmens integriert wurde. Sie stellte den größten Zuwachs der Carolina in dieser Zeit überhaupt dar und zeigte zugleich das breite Spektrum, sowohl inhaltlich-thematisch als auch formell, d. h. es sind hier schon ziemlich viele Wiegendrucke aus der Zeit vor 1490 zu finden. Das bedeutet wohl, dass Koranda seine Bibliothek seitdem kaum weiter ausbaute, obwohl er erst 1519 im gesegneten Alter starb. Mareks Evidenz zufolge haben sich 71 Bände erhalten, vereinzelte sogar an ganz unerwarteten Stellen im Ausland (Thorn, Wien), so dass man vermuten darf, dass er in seinen letzten Lebensjahren auch verschiedentlich mit ihnen disponierte. Von den 25 Inkunabeln stammt nur eine einzige aus dem sonst reichlichen Prager Angebot des Wormser Buchdruckers und -händlers Peter Drach, dessen Agent Schmidhofer in Prag agierte. ${ }^{48}$ Aus der Produktion des ziemlich nahestehenden Anton Koberger aus Nürnberg, dessen Produkte sonst oft in Böhmen belegt sind, findet man kaum etwas. Dagegen sind ziemlich viele venezianische Drucke vorhanden, obwohl sie meist jünger sind, um direkt mit Korandas Italienaufenthalt (1462) verknüpft werden zu können. So müssen sie als eine nicht näher charakterisierbare Italien-Reminiszenz gelten. ${ }^{49}$ Aber auch sonst fühlte sich Koranda dem Buchdruck nahe. Er besaß nämlich etliche tschechische Drucke, ja er galt in dieser Hinsicht sogar als Autor. ${ }^{50}$

Sein handschriftliches Buchgut orientierte sich vornehmlich an zwei Bereichen. Einerseits war das die reformatorische Literatur von Wyclif über Hus bis hin zu den Autoren der daran anknüpfenden reformatorischen Generationen, andererseits handelte es sich um die Klassiker der theologischen Literatur, besonders der über die Eucharistie, aber auch um Spezialliteratur aus Mathematik und Astronomie. Doch können wir auch seine bibliophilen Neigungen wahrnehmen. Bezeugt wird dies namentlich durch die wichtige, wohl älteste erhaltene Handschrift der Cosmas-Chronik aus der Zeit um 1200. Leider kann diese Spur nicht weiter zurück verfolgt werden; zu vermuten ist, dass die Handschrift aus einem böhmischen (Benediktiner-?)kloster stammte. Etliche kalligraphisch geschriebene und mäßig geschmückte (juristische) Handschriften ließ Koranda für sich selbst kopieren. ${ }^{51}$

46 E. Gregorovičová, Soukromé knihovny, S. $69 \mathrm{ff}$.

47 Vgl. Jindřich MAREK, Václav Koranda mladší. Utrakvistický administrátor a literát [Wenzel Koranda. Ein utraquistischer Administrator und Literat], Praha 2017, vornehmlich S. 108-146.

48 Vgl. Ivan HlaváčEK, Pronikání cizich prvotiskỉ do českých knihoven v 15. století [Das Eindringen fremder Inkunabeln in böhmische Bibliotheken im 15. Jahrhundert], in: Lubomír Vebr (ed.), Knihtisk a Universita Karlova. K 500. výročí knihtisku v českých zemích, Praha 1972, S. 69-75. Zu Drach und Böhmen s. Ferdinand Geldner, Das Rechnungsbuch des Speyerer Druckherrn, Verlegers und Großbuchhändlers Peter Drach, Börsenblatt für den deutschen Buchhandel, Frankfurter Ausgabe 18, 1962, Heft 42a, S. 885-972, und jüngst in breiterem Kontext Hendrik MÄKeler, Das Rechnungsbuch des Speyerer Druckherrn Peter Drach d. M., St. Katharinen 2005.

49 Vgl. dazu auch Ivan HlavÁČEK, Poznámky k italským tiskům v českých knihovnách na konci středověku a počátkem 16. stoleti [Anmerkungen zu den italienischen Drucken in den böhmischen Bibliotheken im ausgehenden Mittelalter und zu Beginn des 16. Jahrhunderts], in: Národní knihovna České republiky. Miscellanea Oddělení rukopisů a starých tisků 13, 1996, S. 39-52.

50 J. MAReK, Václav Koranda, S. 143.

51 J. MAreK, Václav Koranda, S. 127. 
Auch aus dem ausgehenden 15. und beginnenden 16. Jh. nur einige Beispiele. So brachte Stanislaus von Welwarn (Velvary) mehrere theologische bzw. juristische Handschriften aus Paris mit, die dann im Kolleg kopiert wurden, ${ }^{52}$ Wenzel aus Saaz schenkte eine spezielle mathematisch orientierte Bibliothek, Michal von Stráž ebenfalls, oder Vitus Salier mit dem Legat von mehr als gut einhundert Bänden im Jahre 1520 usw. ${ }^{53}$ Nun handelte es sich hierbei freilich überwiegend um Drucke, die bald das Feld eroberten und die nicht nur aus dem Reich, sondern auch aus Italien, zumeist aus Venedig herrühren. Auch der Buchhandel intensivierte sich, obwohl wir längst nicht alles, wiewohl gewünscht, darüber wissen. Die Arbeiten von Zdeněk Šimeček sind jedoch ein guter Ausgangspunkt zu weiteren Forschungen. 54

Obwohl die Universitätsmagister nicht so ,altmodisch“ waren, wie wir es z. B. bei Johann Trithemius beobachten können, wurden sie doch im allgemeinen vom Buchdruck „überrascht“ und haben eben eine geraume Zeit gebraucht, um sich zu orientieren. Ihre Reaktion war anfangs bis zu einem gewissen Grad widersprüchlich, bald aber, vornehmlich ab Mitte des 16. Jh., nur allzu oft äußerst pragmatisch, was sich darin äußerte, dass sie „unleserliche und unbrauchbare“ Handschriften haufenweise käuflich anboten, um Gelder für neue Ankäufe zu gewinnen. ${ }^{55}$ Angebote erfolgten auch im Rahmen der Universität, was freilich wegen totalen Mangels an diesbezüglichen Rechnungen kaum genauer verfolgt werden kann. ${ }^{56}$ Als Beispiel für grenzüberschreitende Kontakte ist auf die Rezeption des modernen französischen Philosophen Jean Versor in Prag Mitte des 15. Jh. hinzuweisen, wie das František Šmahel vor längerer Zeit anschaulich dargelegt hat. ${ }^{57}$

Daran anschließend soll unsere Aufmerksamkeit kurz einer anderen interessanten Gestalt der letzten Jahre der selbständigen Carolina gelten, nämlich dem schon erwähnten Vorstand ihres Allerheiligenkollegs, dem Magister Johannes Adam Bistřický (Bystřický) von Buchau. Im ersten Band der eingangs zitierten großen Universitätsgeschichte erscheint er nur in der Rektorenliste, wo er knapp als Bystrziczenus (z Bystřice) vorkommt. Dennoch muss es sich bei ihm um eine interessante Persönlichkeit handeln, die unsere Aufmerksamkeit verdient - eben der Bücher wegen. ${ }^{58}$ Überraschenderweise hat Kampanus, der ein

52 Siehe Eva Gregorovičová, Knihovna mistra Stanislava z Velvar [Die Bibliothek des Magisters Stanislaus von Welwarn], HUCP 18/1,1978, S. 107-127, wo dank ihrer Kolophone weitere Bände analysiert werden können, die auch den heimischen Bücherverkehr zu verfolgen gestatten. Vgl. auch DiEs., Z rukopisného bohatství Národni knihovny. Soukromá knihovna M. Stanislava z Hnězdna. Jeji funkce a význam [Aus dem handschriftlichen Reichtum der Nationalbibliothek. Die Privatbibliothek von M. Stanislaus von Gnesen. Ihre Funktion und Bedeutung], in: Manu propria. Sborník příspěvků k životnímu jubileu PhDr. Aleny Richterové CSc., Praha 2012, S. 35-50.

53 Alles bei Kampanus verzeichnet, jedoch nur allzu lakonisch.

54 Zdeněk ŠIMEČEK, Geschichte des Buchhandels in Tschechien und in der Slowakei, Wiesbaden 2002; DERS., Knižni obchod v Brně od sklonku 15. do konce 18. století [Der Buchhandel in Brünn vom Ausgang des 15. bis Ende des 18. Jahrhunderts], Brno 2011, und Ders. - Jiří TrávníčEK, Knihy kupovati. Dějiny knižního trhu v českých zemích [Bücher kaufen. Die Geschichte des Buchmarktes in den böhmischen Ländern], Praha 2014. Vgl. auch Ivan HLAVÁČEK, Poznámky k italským tiskům.

55 Mehrere Belege bei Z. WinTer, O životě na vysokých školách, besonders S. 377-385.

56 Auch die einzigen systematischen Rechnungen, die sich erhalten haben, bringen kaum etwas. Vgl. Mlada Holá - Martin Holý (Hgg.), Das Studentenkolleg der Böhmischen Nation der Prager Universität. Edition der Rechnungen aus den Jahren 1541-1611, Berlin - Münster 2019, S. 64, 188, 282, 377 und 383.

57 Vgl. František Šmahel, Paris und Prag um 1450. Johannes Versor und seine böhmischen Schüler, Studia źródłoznawcze 25, 1980, S. 67-77.

58 Viele Einzelbelege bei dem oben zitierten Z. WINTER, O životě na vysokých školách, dem Register zufolge. Eine knappe Biographie findet man in: Josef HeJNIC - Jan MARTíneK (edd.), Rukovět humanistického básnicví. 
enger Zeitgenosse des Johannes, ja sein Freund war, seiner Bibliothek oder besser seinem großen donum bzw. Vermächtnis in seinem Calendarium keine Aufmerksamkeit geschenkt, was umso mehr überrascht, da Bystřický literarisch rege tätig war, wozu er freilich ein fachliches Hinterland benötigte: also Bücher. Ihr Profil haben die Autoren des Enchiridions wie folgt zusammengefasst: danach handelte es sich um Auslegungen antiker Klassiker, besonders der Ethik des Aristoteles oder der Werke Ciceros. Es folgten Plato, Quintilian, Ovidius, Seneca, Plotin, Komödien des Plautus, Cicero gar in tschechischen Übersetzungen! Das teilweise Fehlen der Aristotelica, die Bystřický las, bedeutet, dass das Verzeichnis nicht ganz vollständig sein kann, denn auch in „seiner“ Kollegienbibliothek sind diese Texte nicht aufzufinden. Weiter ist dort die Schullektüre reichlich vorhanden. Man findet dort verschiedene Lexika, Grammatiken aller sich anbietenden Sprachen: Griechisch, Lateinisch, Tschechisch und Deutsch. Alles aber erklärt die Beschreibung seiner Wohnung nach seinem Tod, in der man liest, dass sich dort zwei Büchergestelle voll von Büchern befanden. Wieviel Bände waren es? Sicher mehr als im erhaltenen Inventar verzeichnet. Sonst weiss man nichts. ${ }^{59}$

Ein anderer Zeitgenosse Korandas, Rektor M. Michael von Stráž († 1512), hat sein ganzes mathematisches und theologisches Büchergut der almae matri vermacht. Auch aus dem 16. Jahrhundert sind mehrere Magisterbibliotheken belegt. Manche haben nach Kampanus' Zeugnis wieder in den Kollegienbibliotheken Zuflucht gefunden, über weitere weiß man aus anderen Quellen Bescheid, und die übrigen sind fast mit Sicherheit vorauszusetzen. Die Parole „kein Magister ohne eigene Bibliothek“ liegt auf der Hand, so dass man buchstäblich ihrer Aberdutzende voraussetzen muss. Deshalb sieht man, dass auch die folgenden Generationen sich nicht bloßstellen ließen. Dies nur zur Illustration: M. Wenzel von Saaz hat dem Großen Kolleg (d. h. dem Carolinum) namentlich mathematische Bücher geschenkt (1520), M. Lorenz von Třeboň/Wittingau bedachte mit seinem Büchergeschenk die universitäre Bethlehemskapelle, 1557 schenkte M. Johann Hortensius Ciceros Werke, Wenzel Zelotin von Schönberg (Krásná Hora) stiftete dem Karolinum Hussens und Homers opera. Gallus Gelastus Vodnianus vermachte seine vielartige Büchersammlung nicht der Universität, sondern seinem Geburtsort, wo sie sich teilweise bis heute befindet. Hervorzuheben ist auch das Büchervermächtnis des herausragenden Humanisten und begabten Literaten Sebastian Aerichalcus. ${ }^{60}$

Es hätte wenig Sinn, einen Katalog von Bibliotheksschenkungen zu präsentieren, doch kann man vielleicht wie folgt resümieren: die Bibliotheken der Prager Universitätsmagister bilden eine spezifische Kategorie von Bibliotheken, wie das eingangs angedeutet wurde, jedoch stets unter Wahrung des Möglichen im Rahmen des Königreichs, obwohl ein breiterer Vergleich wünschenswert wäre. ${ }^{61}$ Als soziale Gruppe, die jedoch mit dem lokalen Bürgertum eng verknüpft war, bildeten ihre Inhaber den wichtigsten und spezifischen Teil

Enchiridion renatae poesis [Vademecum der humanistischen Dichtkunst in Böhmen und Mähren. Enchiridion renatae poesis], I, $A-C$, Praha 1966, Stichwort Adami (Adamides, Bistricenus, Bystřický), S. 43f. Obwohl er das Attribut von Buchau (Bochov in Westböhmen) trug, hielt das Vademecum das südmährische Býkovec unweit von Telč für seine wahrscheinliche Geburtsstätte.

59 Dvě repositoria byla ve světnici knihami plná [Zwei Büchergestelle befanden sich in einer Kammer voller Bücher], in: J. TeIgE, Základy, S. 193a.

60 Siehe Rukovět', I, S. 9ff.

61 Vorläufig ist auf den knappen Versuch J. Mareks, Koranda, S. 136ff., hinzuweisen, der neben heimischer Materie auch die Krakauer Verhältnisse reflektiert. 
der städtischen kulturellen (intellektuellen) Elite, was nicht zuletzt eben ihre Bibliotheken und ihr Inhalt verdeutlichten. ${ }^{62}$ Und da sowohl Prag als auch die Universität im Königreich Böhmen unangefochten an der Spitze standen, waren auch Bibliotheken der Universitätsmagister ein spezifisches und bis zu einem hohen Grad einzigartiges Phänomen des utraquistischen Böhmen. Ein ausführlicherer Vergleich der Inhalte dieser Bibliotheken mit denen der bürgerlichen utraquistischen, aber auch mit denen der katholischen Intelligenz und freilich auch mit denen der deutschen Protestanten in Böhmen scheint aktuell zu sein. Verschiedene Ansätze monographischer Art sind hier zu verzeichnen. ${ }^{63}$

Aber noch ein anderer Vergleich scheint mir wichtig, nämlich der mit den Verhältnissen an den mitteleuropäischen Nachbaruniversitäten Krakau, Leipzig, Heidelberg, Wien und für die Frühe Neuzeit auch mit den neu entstandenen, sozusagen modernen Institutionen. Auch aus dem entfernteren Frankreich steht seit Kurzem ein dem Titel nach vielversprechendes Buch zur Verfügung; tatsächlich aber werden darin Nutzung und Verwaltung der Kollegienbibliotheken in Paris behandelt, nicht die der Magister. ${ }^{64}$ Dass also alles private Buchgut stets in engstem Zusammenhang mit der Geschichte der diesbezüglichen institutionellen Bibliotheken interpretiert werden muss, braucht man nicht besonders hervorzuheben. Um einen ersten Versuch für die Zeit um und nach 1500 hat sich schon J. Marek mit einem knappen internationalen Vergleich bemüht, für die nachfolgenden Jahrzehnte dann Petr Voit, ${ }^{65}$ dessen Skizze ziemlich düster ist. Ich möchte hoffen, dass weitere Arbeiten über das angesprochene Thema die Prager und allgemein die böhmische Situation in helleren Farbtönen zeigen mögen, besonders wenn man auch die Brüderunität und ihr Bemühen hinzuzieht. Jedenfalls scheint es, dass sich die Prager Akademie, was die Bücherausstattung anbelangt, nicht zu schämen braucht.

Damit hoffe ich, ein Kaleidoskop der Schicksale von Büchern und Bibliotheken der alten Carolina und ihrer Mitglieder geboten zu haben. Und ich schließe mit der Einsicht: relativ viel wissen wir zwar, bedeutend mehr wissen wir aber noch nicht. Jedoch gibt es Wege zur tieferen Erforschung dieses interessanten Phänomens unserer älteren Universitäts- und Kulturgeschichte. Es sind zwar keine Autobahnen, sondern eher Pfade, die aber doch weiter führen und Ergebnisse bringen können. Nur den Willen braucht es.

(Deutsche Fassung: Autor; sprachliche Korrektur: Wolf B. Oerter)

62 Ohne mich in die Problematik des Begriffes „Elite“ einmischen zu wollen, müssen zwei diesbezügliche Aufsätze zitiert werden: Marie BlÁHovÁ, Pražská inteligence v pozdním středověku [Die Prager Intelligenz im Spätmittelalter], Documenta Pragensia 22, 2004, S. 51-66, und besonders Blanka ZiLYnskÁ, Die intellektuellen Eliten der Stadt Prag im Mittelalter, in: Michael Diefenbacher - Olga Fejtová - Zdzisław Noga (Hgg.), Krakau - Nürnberg - Prag (Documenta Pragensia - Monographia 33/1), Praha 2016, S. 393-414. Übrigens sind in der soeben zitierten Publikation auch weitere Beiträge zum Thema zu finden, auch über Krakau: Krzystof Oźóg bespricht die Eliten allgemein, Maciej Zdanek widmet sich dem universitären Bereich, doch standen die diesbezüglichen Bibliotheken dort nicht auf dem Programm. Es gibt jedoch ältere Literatur zum Thema, so besonders Wacława SzELIŃSKA, Biblioteki profesorów Uniwersytetu krakowskiego w XV i poczatkach XVI wieku [Die Professorenbibliotheken der Universität Krakau im 15. und zu Beginn des 16. Jahrhunderts], Wrocław Warszawa - Kraków 1966

63 So besonders für die Frühe Neuzeit, wobei vornehmlich die Studien von Olga Fejtová, Jiří Pešek und Václav Bok mit grossem Nutzen zur Verfügung stehen.

64 Claire ANGOTTI - Gilbert Fournier - Donatella NebBiai (Hgg.), Les livres des maîtres de Sorbonne. Histoire et rayonnement du collège et de ses bibliothèques à la renaissance, sous la direction de..., Paris 2017.

65 Jüngst Petr Vort, Česká knižní kultura doby Václava Hájka z Libočan [Die böhmische Buchkultur zu Zeiten Wenzel Hajeks von Libočany], Česká literatura 62, 2014, S. 161-183. 


\section{Finanzielle Förderung:}

Der Aufsatz entstand im Rahmen des Projekts Nr. GA18-00408S „Universitas magistrorum. Professoren der Prager utraquistischen Universität (1458-1622)“ der Tschechischen Agentur zur Förderung der wissenschaftlichen Forschung (Grantová agentura České republiky).

\section{IVAN HLAVÁČEK}

\section{KNIHOVNY MISTRŮ PRAŽSKÉ UNIVERZITY NA KONCI STŘEDOVĚKU A V RANÉM NOVOVĚKU}

\section{RESUMÉ}

Protože kniha jako taková a interpretace nejrůznějších textů byly podstatnou částí funkce univerzitního vzdělávání, je př́tomnost knihoven na univerzitách zásadní součástí jejich existence. Vedle kolejních knihoven byly na pražské univerzitě - tak jako jinde - jejich důležitým pendantem knihovny univerzitních mistrů. Jejich počet se v podstatě rovnal počtu samotných přednášejících, i když pokud jde o jejich dochování, je situace takřka kritická. Nejenže nejsou dochovány jako celky, ale i jinak jde o torza, která většinou anonymně vcházela dříve či později do knihoven kolejních. Ty jsou nadto rovněž dochovány jen velmi torzovitě. Na základě vlastnických záznamů, starých knihovních soupisů, př́ípadně dalších zmínek se autor snaží stručně charakterizovat tyto soubory a jejich osudy. Dochází přitom k závěru, že knižní kultura byla na pražské univerzitě (přes pohromy, které ji potkávaly) na mimořádné úrovni, což se týkalo i doby přechodu od knihy psané ke knize tištěné. Šlo prritom nejen o jejich rozsah (některé knihovny výrazně překračovaly i sto svazkủ), ale také o obsah. Na detailní rozbor dochovaného materiálu (především tu jde o dvě dnešní knihovny, které jej uchovávají, a sice o Národní knihovnu České republiky a Knihovnu pražské kapituly) je ovšem třeba ještě počkat. Autor upozorňuje i na některé metodologické otázky. Detailní analýzy se zatím dostalo jen několika málo z nich: Václavu Korandovi mladšímu, Václavu Křižanovskému a nemnoha dalším.

prof. PhDr. Ivan Hlaváček, CSc.

Katedra PVH a archivního studia FF UK

ivan.hlavacek@ff.cuni.cz 